\title{
IMPLEMENTASI KEBIJAKAN PROGRAM BANTUAN LANGSUNG TUNAI (BLT) TERHADAP WARGA TERDAMPAK COVID-19 DI DESA CIBADAK
}

\author{
Fika Nurahmawati ${ }^{1}$ dan Sri Hartini ${ }^{2}$ \\ fikanurrahma21@yahoo.com ${ }^{1}$ \\ srihartini@uika-bogor.ac.id ${ }^{2}$ \\ Fakultas Hukum Universitas Ibn Khaldun, Bogor ${ }^{1,2}$
}

\begin{abstract}
ABSTRAK
BLT (Bantuan Langsung Tunai) merupakan salah satu tindakan yang diambil oleh pemerintah kita untuk memberikan subsidi kepada masyarakat yang membutuhkan di Indonesia.Tingkat kesejahteraan di negara kita dianggap masih sangat kuramg dikarenakan masih begitu banyak masyarakat yang memiliki kehidupan yang kurang layak yang diakibat oleh beberapafaktor seperti pengangguran, kelaparan, kemiskinan, dan lain-lain. Apalagi ditengah pandemi covid19 banyak sekali masyarakat yang kehilangan mata pencahariannya karena dirumahkan ataupun perusahaan tempat bekerja bangkrut maka dari itu pemerintah membuat kebijakan bantuan berupa dana maupun kebutuhan pangan bagi masyarakat Indonesia. Penelitian ini bertujuan untuk mengetahui sudah sesuaikah pembagian bantuan di desa ini sesuai dengan regulasi pemerintah.Data penelitian dikumpulkan dengan mengunakan instrumen kuesioner, interview, dan observasi.
\end{abstract}

\section{Kata Kunci: BLT (Bantuan Langsung Tunai), Implementasi Kebijakan Program, Terdampak Covid-19.}

\section{PENDAHULUAN}

Bantuan Langsung Tunai (bahasa Inggris: cash transfers) atau disingkat BLT di Indonesi adalah program bantuan pemerintah berjenis pemberian uang tunai atau beragam bantuan lainnya, baik bersyarat (conditional cash transfer)maupuntak bersyarat (unconditional cash transfer) sesuai dengan Peraturan Pemerintah Republic Indonesia Nomor 60 Tahun 2014 Tentang Dana Desa Yang Bersumber Dari Anggaran Pendapatan Dan Belanja Negara. Negara yang pertama kali memprakarsai BLT adalah Brasil, dan selanjutnya diadopsi oleh negara-negara lainnya. Besaran dana yang diberikan dan mekanisme yang dijalankan dalam program BLT berbeda-beda tergantung kebijakan pemerintahdi negara tersebut. Indonesia juga merupakan negara penyelenggara BLT, dengan mekanisme berupa pemberian kompensasi uang tunai, pangan, jaminan kesehatan, dan pendidikan dengan target pada tiga tingkatan: hampir miskin, miskin, sangat miskin. BLT dilakukan pertama kali pada tahun 2005, berlanjut pada tahun 2009 dan di 2013 berganti nama menjadi Bantuan Langsung Sementara Masyarakat (BLSM). Indonesia termasuk Negara yang paling sukses menyelenggarakan bantuan berjenis langsung tunai kepada masyarakat miskin dibandingkan Negara lain. Hal ini mereka 
buktikan dengan laporan tri wulanan ketiga pada tahun 2010.Dalam laporan itu mereka berkomentar pemerintah Indonesia berhasil menyalurkan kepada sepertiga rumah tangga di Indonesia hanya dalam waktu kurang dari 5 bulan.Penyaluran ke keluarga sasaran di Indonesia juga dinilai tepat waktu oleh Bank Dunia, dan hal itu berdampak positif pada pembangunan masyarakat dan menjadi insentif bagi yang tidak produktif. Program BLT juga sebagai salah satu program yang bertujuan menurunkan jumlah warga miskin Hal itu dia buktikan dengan bukti bahwa pada tahun 2007 warga miskin berjumlah 37 juta, namun berkurang pada tahun 2008 menjadi 35 juga warga miskin. untuk warga terdampak covid -19 BLT dapat menjaga daya beli masyarakat dan melepas keterpurukan. Untuk saat ini mengenai penanggulangan dampak dari covid -19 agar masyarakat tetap sejahtera pemerintah pun mengeluarkan sebuah kebijakan bantuan dana yang berupa BLT yang dimana warga itu sendiri kehilangan pekerjaan nya sebagai sumber dana kehidupan sehari hari. Pemerintah terus menghadirkan program bantuan langsung tunai (BLT) bantuan sosial hingga subsidi untuk membantu warga di tengah pandemi Covid-19 hingga Desember 2020. Meski terdapat program bantuan yang harus ditunda karena membutuhkan waktu untuk melakukan verifikasi data penerima bantuan. Misalnya BLT bagi pekerja anggota aktif BPJS Ketenagakerjaan yang memiliki upah di bawah Rp5 juta per bulan. Program ini terpaksa ditunda sebab Kementerian Ketenagakerjaan masih membutuhkan waktu untuk check list data. Selain itu, pemerintah juga menyiapkan subsidi bagi Usaha Mikro Kecil dan Menengah (UMKM), subsidi listrik, bantuan sosial melalui program Kartu
Prakerja dan BLT Dana Desa. Syarat penerimanya adalah keluarga miskin yang bukan termasuk penerima Program Keluarga Harapan (PKH), tidak memperoleh Kartu Sembako dan Kartu Prakerja. Dalam pelaksanaannya meliputi tahap pendataan calon penerima yang mengacu pada data terpadu kesejahteraan sosial (DTKS), data warga miskin (SK Bupati), warga miskin kehilangan pekerjaan, atau memiliki anggota keluarga mempunyai penyakit kronis, serta warga miskin terdampak ekonomi karena kehilangan pekerjaan. Pendataan calon penerima BLT Desa nempertimbangkan Data Terpadu Kesejahteraan Sosial (DTKS) dari Kementerian Sosial.Ketentuan mengenai mekanisme pendataan, penetapan data penerima manfaat, dan pelaksanaan pemberian BLT Desa dilakukan sesuai ketentuan Menteri Desa PDTT.Besaran BLT adalah Rp600.000/bulan/ Keluarga Penerima Manfaat (KPM) yang diberikan selama 3 bulan, yaitu April hingga Juni 2020. BLT dianggarkan dalam APBDesa maksimal sebesar 35\% dari Dana Desa atau lebih dengan persetujuan pemerintah kabupaten/kotamadya. Penyaluran Dana Desa juga dipermudah melalui penyederhanaan dokumen dan penyaluran yang diupayakan agar lebih cepat.Kepala Desa merupakan pihak yang bertanggung jawab atas penggunaan, penyaluran hingga pertanggung jawaban BLT Desa. BLT Dana Desa merupakan program prioritas yang harus dianggarkan oleh Pemerintah Desa. Jika Pemerintah Desa tidak menganggarkan BLT Dana Desa, Pemerintah Desa akan dikenakan sanksi mulai dari pemotongan sebesar $50 \%$ untuk penyaluran Dana Desa tahap berikutnya hingga penghentian penyaluran Dana Desa Tahap III. Teknis pembagian BLT-DD dilaksanakan memenuhi protokol 
pencegahan Covid-19 dengan mengundang penerima secara bergiliran, tempat duduk antrian berjarak aman, menyediakan tempat

\section{METODE PELAKSANAAN}

Metode ini saya lakukan dengan mengumpulkan data berdasarkan kuesioner, interview, dan observasi yang merupakan salah satu jenis pengumpulan data yang terdapat dalam metode penelitian kualitatif. Karena di pelaksanaan KKN kali ini agar kita dapat mengetahui apakah prosedur pembagian BLT di desa Cibadak ini sudah sesuai dari regulasi pemerintah atau belum serta hambatan kelancaran dan pelaksanaan pembagian BLT ini kepada warga maka dari metode kualitatif yang saya pilih ini cocok untuk mengetahui semua pertanyaan pada penelitian kali ini. Tahap pertama, saya mengumpulkan beberapan data dan besaran dana yang telah tersalur dengan uji kelayakan nya di kantor desa Cibadak. Saya mencoba untuk menjabarkan pembagian BLT tersebut sudah sesuai dengan prosedur apa belum sesuai pendataan warga yang menerima nya. karena metode yang saya ambil yaitu metode kualitatif maka dari itu saya

\section{HASIL DAN PEMBAHASAN}

Kuesioner, Interview dan Observasi sebagai cara dalam pengumpulan data yang saya lakukan menjadi tahap akhir dalam penelitian ini. Setelah itu saya mengajukan 5 pertanyaan dalam bentuk quisioner kepada beberapa masyarakat cibadak yang berkaitan dengan pembagian dana BLT di desa ini sekaligus untuk mengetahui apakah warga mendapatkan hak nya dengan baik melalui program bantuan pemerintah ini.

Kuesioner kepada warga Cibadak seputar BLT cuci tangan/hand sanitizer, dan memakai masker.

melakukan kerja lapangan langsung bersama dan beraktivitas dengan orang orang yang diteliti untuk mendapatkan keabsahan data, tahap selanjutnya yaitu interview dan melakukan observasi saya akan mendatangi beberapa dari banyak penerima. BLT untuk meyakini bahwa pemberian BLT berjalan sesuai dengan data yang sebelumnya saya dapat di kantor desa. Hasil dari penelitian ini selanjutnya diharapkan dapat memberikan manfaat yang berguna sebagai referensi kebijakan pemerintah desa Cibadak dalam menanggulangi kemiskinan serta mengajak pemerintah daerah desa Cibadak untuk lebih memperhatikan masyarakat di daerah setempat terkait perekonomiannya. Dan juga hasil penelitian ini dapat dijadikan sebagai masukan bagi yang hendak melakukan penelitian mengenai Analisis Program BLT di daerahnya guna aman, menyediakan tempat cuci tangan/hand sanitizer, dan memakai masker.

1. Apakah pendistribusian BLT di desa ini telah merata kepada seluruh warga cibadak?

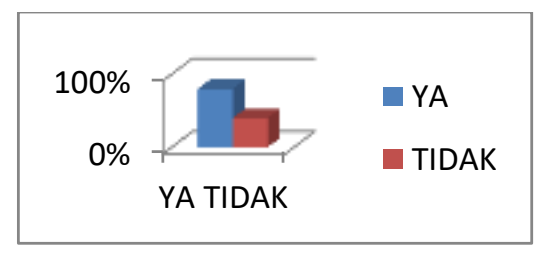

2. Cukup membantukah program pembagian BLT ditengan pandemi ini? 


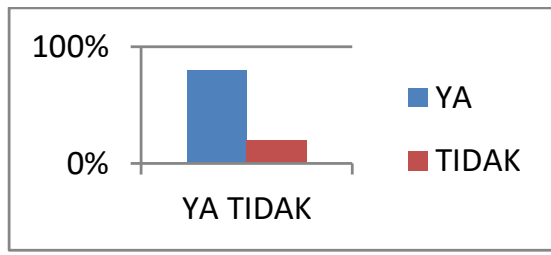

3. Saudara/i penerima bantuan terdampak covid ini berupa BLT atau Sembako?

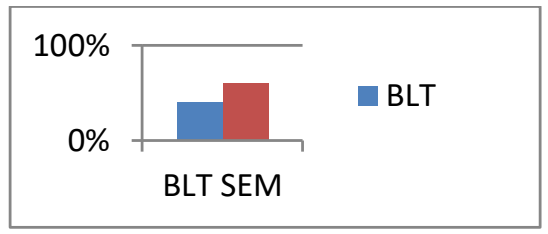

4. Ketepatan waktu dalam pembagian bantuan berupa BLT apakah selalu tepat?

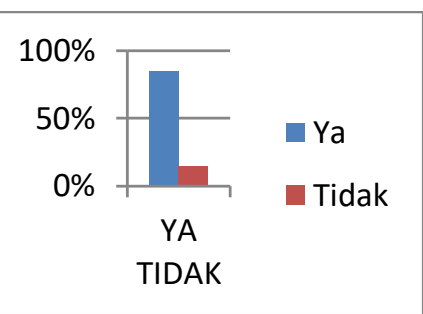

5. Dari keseluruhan pembagian BLT selama ini apakah saudara/i sudah merasa terpenuhi hak nya sebagai warga terdampak covid-19?

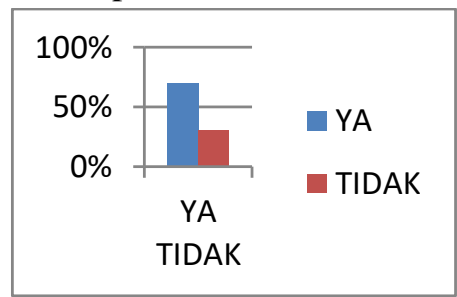

Interview 5 pertanyaan kepada kepala desa dan staff mengenai pembagian BLT-DD ini

\begin{tabular}{|c|c|c|}
\hline $\mathrm{No}$ & Pertanyaan & Jawaban \\
\hline 1 & $\begin{array}{l}\text { Apakah Bantuan Langsung } \\
\text { Tunai (BLT-Dana Desa) bisa } \\
\text { dibagi rata untuk semua } \\
\text { penduduk yang terdampak } \\
\text { covid-19? }\end{array}$ & $\begin{array}{l}\text { Pemerintah sudah menyiapkan } \\
\text { pintu2 bantuan dalam bentuk lain } \\
\text { bagi warga yg tidak menerima } \\
\text { bantuan secara tunai, misalnya } \\
\text { sembako. Dalam hal ini program } \\
\text { Pemdes tidak lepas dari program } \\
\text { Pemerintah pusat, jika anggaran } \\
\text { desa tidak mencukupi, ada } \\
\text { bantuan dalam bentuk lain dr } \\
\text { pemerintah pusat. BLT DD hanya } \\
\text { diperuntukan keluarga kurang } \\
\text { mampu }\end{array}$ \\
\hline 2 & $\begin{array}{lrr}\text { Bagaimana Jika } & \text { Anggaran } \\
\text { yang Dialokasikan } & \text { tidak } \\
\text { Mencukupi karena } & \text { Jumlah } \\
\text { Keluarga Miskin } & \text { Terlalu } \\
\text { Besar } & & \end{array}$ & $\begin{array}{l}\text { Memang sudah ada anggaran nya } \\
\text { (semuadesa)yg semula } \\
\text { dianggarkan buat Pembangunan } \\
\text { Infra struktur (pengaspalan, } \\
\text { Betonisasi.dll) karna merebaknya } \\
\text { Wabah Covid } 19 \text { ada Surat dari } \\
\text { Pusat (Kemendes) untuk Dana } \\
\text { Desa dialihkan ke Penanganan } \\
\text { Covid } 19 \text { jadi kita mengikuti jd } \\
\text { tdk ada Pembangunan phisik }\end{array}$ \\
\hline 3 & $\begin{array}{l}\text { Bagaimana jika desa tidak } \\
\text { menganggarkan BLT- Dana } \\
\text { Desa? }\end{array}$ & $\begin{array}{l}\text { Pelaksanaan jlnnya pemdes selalu } \\
\text { berkoordinasi ketat dgn } \\
\text { pemerintahan diatasnya. } \\
\text { Kemungkinannya kecil bila } \\
\text { pemdes tdk menganggarkan blt }\end{array}$ \\
\hline
\end{tabular}




\begin{tabular}{|l|l|l|}
\hline & & $\begin{array}{l}\text { dlm pengelolaan anggaraannya. } \\
\text { Jika ada desa yg tdk } \\
\text { menganggarkannya mungkin sj } \\
\text { karena kurangnya koordinasi dgn } \\
\text { pemerintahan diatasnya. }\end{array}$ \\
\hline 4 & $\begin{array}{l}\text { Bagaimana tahap pendataan } \\
\text { dan penyaluran BLT-Dana } \\
\text { Desa? }\end{array}$ & $\begin{array}{l}\text { Direkomendasi oleh Ketua RT, } \\
\text { RW, Kepala Dusun dan Badan } \\
\text { Permusywrtn Desa. Dihimpun dan } \\
\text { dimusyawarahkan lagi dlm } \\
\text { musdes bersama muspika desa, } \\
\text { dan disetujui bersama yg } \\
\text { dituangkan dlm Berita Acara } \\
\text { penerima bantuan Dana Desa. }\end{array}$ \\
\hline
\end{tabular}

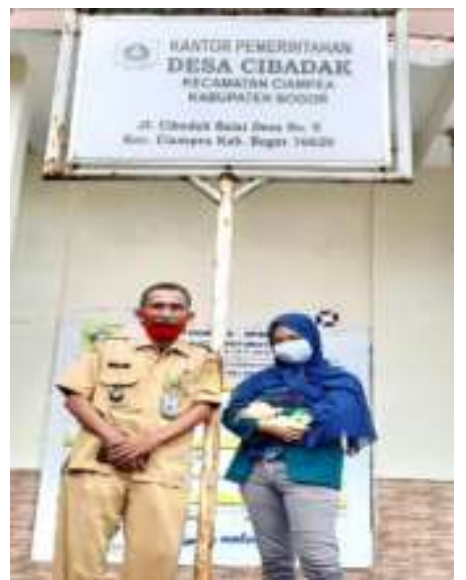

Gambar 1 : Kepala desa Cibadak (kegiatan wawancara mengenai BLT-Dana Desa dengan pemerintahan desa yang diwakilkan oleh kepala desa setempat)

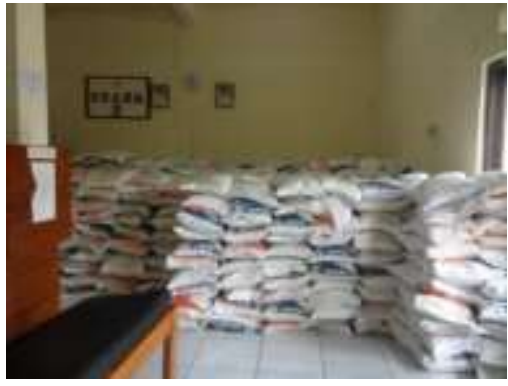

Gambar 2: BLT-Dana Desa dalam bentuk lain selain uang tunai, yaitu beras sekaligus membagikan setelah itu

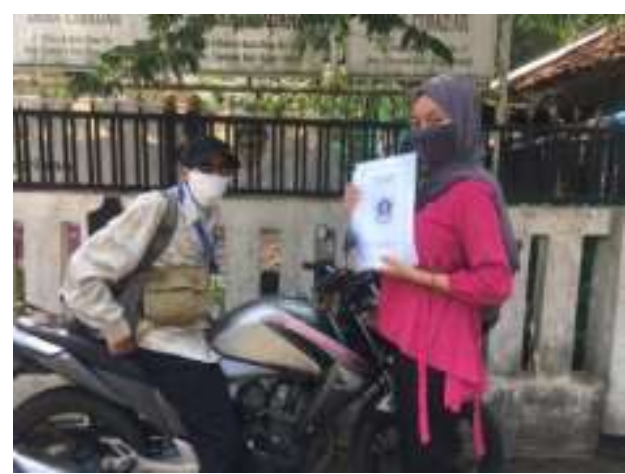

Gambar 3: Kegiatan pengambilan data dengan petugas desa mengenai pembagian blt dan sesnsus penduduk terdampak covid-19 selama ini

Sumber: Warga Cibadak-Kepala Desa CibadakStaff Kelurahan Desa Cibadak. 


\section{KESIMPULAN}

Dalam pembahasan dari kuisioner, wawancara dan observasi diatas tersebut, terdapat beberapa kesimpulan dari setiap point yang dinyatakan yaitu sebagai berikut, hasil dari kuisioner ke 1, menunjukan bahwa $80 \%$ warga Cibadak Raya Kecamatan Ciampea Kabupaten Bogor sudah menerima bantuan dari pemerintah bagi warga terdampak covid19. Hasil dari kuisioner ke 2 menunjukan $80 \%$ cukup terbantu dengan pembagian bantuan dari pemerintah ini. Hasil dari kuisioner ke 3 menunjukan bahwa bantuan dari pemerintah terdampak covid didesa ini tidak hanya berupa uang tunai akan tetapi lebih banyak juga warga juga yang mendapatkan sembako. Yaitu $40 \%$ penerima bantuan berupa BLT sementara $60 \%$ penerima bantuan berupa sembako.Akan tetapi penelitian yang saya

\section{DAFTARPUSTAKA}

Raditya, T. W. (2013). Dampak kebijakan bantuan langsung sementara masyarakat terhadap aktivitas masyarakat di Desa Keboan Anom Kecamatan Gedangan Kabupaten Sidoarjo (Doctoral Dissertation, Upn" Veteran" Jawa Timur).

FINAHARI, R. (2017). Implementasi Kebijakan Tentang Bantuan Langsung Tunai (BLT) Sebagai Program Keluarga Harapan (PKH) Di Desa Penaga Kabupaten Bintan Pada Tahun 2017. ambil disini hanya merupakan bantuan langsung tunai dari pemerintah saja. Hasil dari kuisioner ke4 yaitu menunjukan bahwa $80 \%$ warga menerima bantuan dengan tepat waktu sesuai jadwal2 yang telah ditentukan.Dan hasil dari kuisioner yang terakhir menunjukan bahwa $80 \%$ warga cibadak sudah merasa hak nya terpenuhi sebagai warga negara atas bantuan terdampak covid-19 ini. Adapun prosedur pembagian BLT di desa Cibadak ini yaitu dengan beberapa ketentuan seperti menyerahkan Kartu Tanda Penduduk (KTP) dan Kartu Keluarga (KK) yang beridentitas atau berdomisili sebagai warga Desa Cibadak dan pemilik kartu Program Keluarga Harapan (PKH) untuk warga tidak tetap atau sebagai pendatang baru yang tinggal disebuah rumah kontrak di Cibadak.

Nurhamlin, N., \& MARINI, D. (2015). Dampak Penyaluran Bantuan Langsung Tunai (Blt) terhadap Masyarakat Miskin di Desa Perawang Barat Kecamatan Tualang Kabupaten Siak (Doctoral dissertation, Riau University).

Rahmona, R., Ningrum, I. P., \& Ransi, N. (2016). Sistem Pendukung Keputusan Untuk Menentukan Penerima Bantuan Langsung Tunai (Blt) Dengan Metode Analytical Hierarchy Process (Ahp)(Studi Kasus: Desa Sambuli, Kecamatan Abeli, Kota Kendari). semanTIK, 2(1). 